\title{
A versatile automatic gas-sampling system
}

\author{
H. L. Reed, D. W. Oliver and A. Tavener \\ The Meat Industry Research Institute of New Zealand (Inc.), P.O. Box, 617, Hamilton, New Zealand
}

\section{Introduction}

Commercially available equipment for automatic gas-sampling is both expensive and bulky. Air infiltration into refrigerated areas should ideally be measured with low-cost, portable, automatic gas-samplers, capable of operating in a wide range of ambient temperatures. This paper describes such a sampler. Although the need for portability limits the size of the equipment and therefore the volume of sampled gas, the consequent reduction in accuracy was not significant in this application. Depending on which tracer gas is used, its concentration in the sampled gas can be determined by infra-red spectroscopy or gas chromatography.

The portable gas-sampler was used to determine the infiltration of warm air into a number of single-storey coldrooms with volumes from 4000 to $38000 \mathrm{~m}^{3}$ and various types of door protection [1]. Infiltration was determined by measuring the rate of decay of the tracer gas $\mathrm{SF}_{6}$ (sulphur hexafluoride). If the tracer gas becomes well mixed with the air in the room, the rate at which its concentration, $c$, decreases with time can be related to the rate of air change, $r$ (i.e. the infiltration rate divided by the volume of the room) by:

$$
\ln \left(c / c_{0}\right)=-r t
$$

where $c_{0}$ is the initial concentration and $t$ is the time after injection.

Sulphur hexafluoride can be detected by electron-capture gas chromatography at concentrations down to one part in $10^{13}$ [2]. It is completely harmless to people and products, relatively inexpensive, and thus ideal for tests in large rooms, such as meat cold-stores.

\section{Description}

The sampler mechanism consists of a rotating drum, or turntable, housing a number of vertically positioned, vacuumsealed, $20 \mathrm{ml}$ test-tubes. The turntable is mounted on a vertical axle, which is rotated in steps by a modified uniselector mechanism to position each sampling tube directly beneath a hypodermic needle (figure 1). For measurements of air infiltration into cold-stores 24 test-tubes are used. The hypodermic needle is connected via a flexible tube to a small diaphragm pump, which in turn is connected via tubing to the area from which the gas is to be sampled. A reciprocating mechanism, driven by a pulsed d.c. motor, moves the hypodermic needle downward to penetrate the rubber bung of the sample tube, thereby exposing it to the test atmosphere (figure 2). After a pre-set delay the needle is withdrawn upward from the self-sealing bung. The turntable is rotated in two steps to position the next sampling tube beneath the needle, and an LED starts flashing at $1 \mathrm{~s}$ intervals to indicate that timing is taking place.

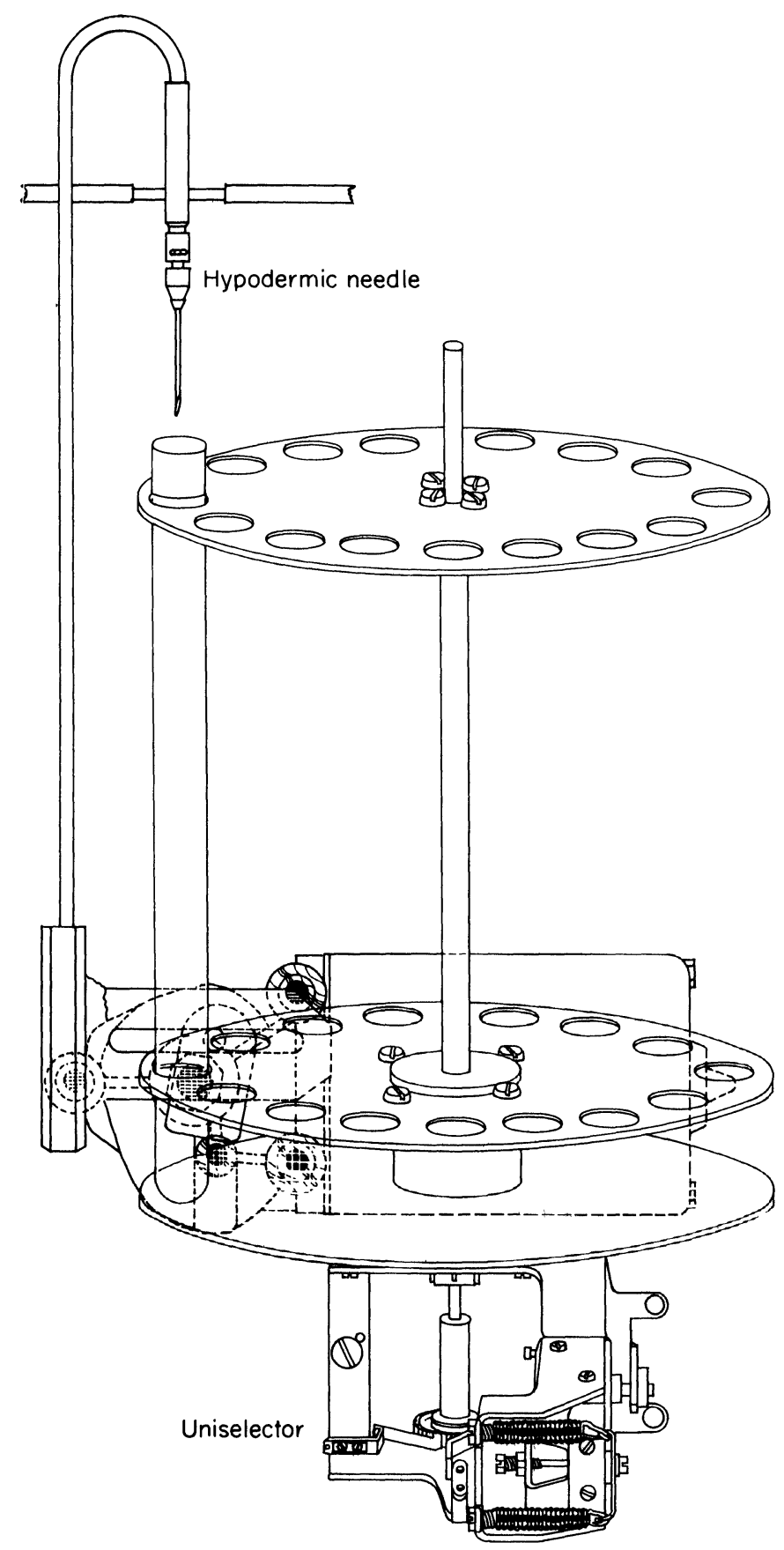

Figure 1. Turntable mechanism. 


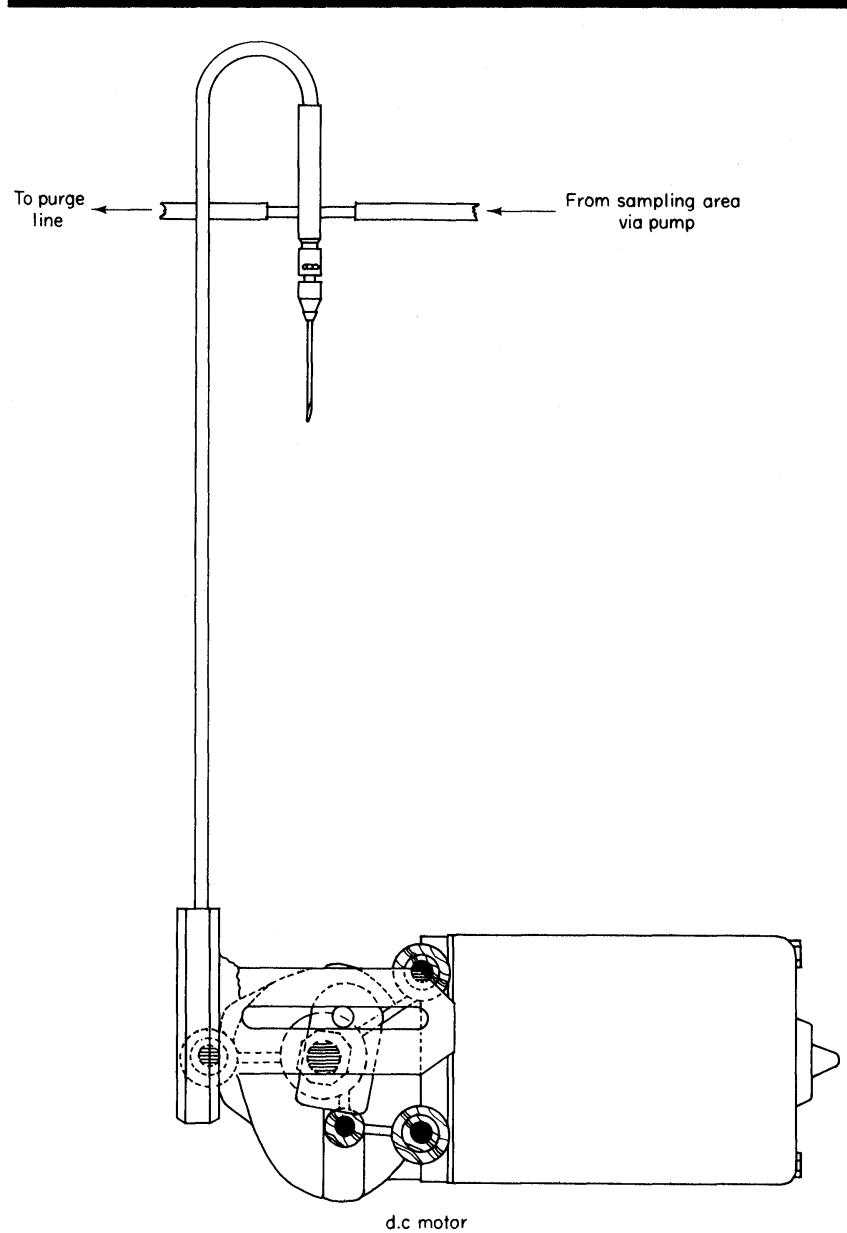

Figure 2. Needle mechanism.

The timing interval is determined by the setting of a decade thumbwheel switch, each digit representing $10 \mathrm{~min}$. Because the thumbwheel switch setting is 'read' at the start of each sampling interval, the interval can be changed during sampling, if required, by changing the switch setting. The sampler will automatically fill all the sample tubes and then stop, regardless of the time interval setting.

The microprocessor not only controls the timing intervals and stepping sequences, it also regulates the torque of the d.c. motor to reduce 'over run' after switch-off. A stand-by battery provides immunity against short-term power failures. A flow diagram is shown in figure 3 and an assembly listing is given in figure 4. Full documentation of the system is available from the authors.

There are six push-button control switches. The 'Auto' button starts the automatic sampling sequence; 'Start test', 'Stop test', 'Reset', 'Motor' and 'Step' buttons allow the operator to check that the automatic control system and mechanism are functioning correctly before the machine is operated in the automatic mode.

\section{Start test}

The Start test button is used to check that the mechanism is functioning correctly. In this mode the motor moves the needle down until it operates a microswitch at the bottom of its stroke. After a short pause the needle is moved up until it operates a microswitch at the top of its stroke. At this point the motor stops and the uniselector is stepped twice to position the next sample tube under the needle, after which the cycle is repeated. This 'fast test cycle' function runs continuously until the Stop test button is pressed.
Stop test

Operation of the Stop test button terminates the 'fast test cycle' at the end of a complete test cycle, at which point an LED glows to indicate that the mechanism and control system are ready for automatic sampling.

\section{Reset}

The Reset button can be used at any point in the sampling sequence to terminate the operation and restore the system to manual control.

\section{Motor}

When the Motor button is depressed, the motor actuating the needle movement turns slowly until the button is released.

\section{Step}

When the step button is depressed, the uniselector steps continuously to rotate the turntable.

\section{Auto}

The Auto button is depressed to start the actual sampling sequence. In this mode the Start test, Stop test, Motor and Step buttons are disabled.

\section{Construction}

The sampler is housed in two metal electrical-distribution cabinets $(457 \times 305 \times 203 \mathrm{~mm})$, each having a hinged door. The cabinets are mounted back-to-back, one containing the electronics and the diaphragm pump, the other containing the sampling tubes and the associated mechanism. The turntable can be tilted forward to enable the sampling tubes to be inserted or removed. Provision is made for the internal stowage of the mains-power lead. The cabinet housing the electronics is partially lined with $25 \mathrm{~mm}$ sheet polystyrene to retain some of the locally generated heat. The total weight of the equipment is $25 \cdot 5 \mathrm{~kg}$.

\section{Applications}

The device can be used for any application in which a gas is sampled to measure its concentration. The only service required is a mains-power supply. Minor circuit changes would enable the sampler to be battery powered. A simple modification to the rotating drum will cater for a different size of test-tube or vial. Commerical pre-evacuated tubes can provide a sampled gas volume accuracy of $\pm 1 \%$ [1]. The sampler can also be used to pre-evacuate sampling tubes by connecting the hypodermic needle to a vacuum pump. The use of a side-entry syringe would allow the device to sample liquids from continuous processes or batch reactions. The physical size, versatility and low cost of the sampler should enable its use as a multi-purpose laboratory apparatus.

\section{References}

1. Pham, Q. T. Air infiltration into cold stores. In Proceedings of 22nd Meat Industry Research Conference (Hamilton, New Zealand, 1982).

2. Grimsrud, D. T., Sherman, M. H., Janssen, J. E., Pearman, A. N. and HARrJe, D. T. ASHRAE Transactions, 86, 1 (1980), 285. 


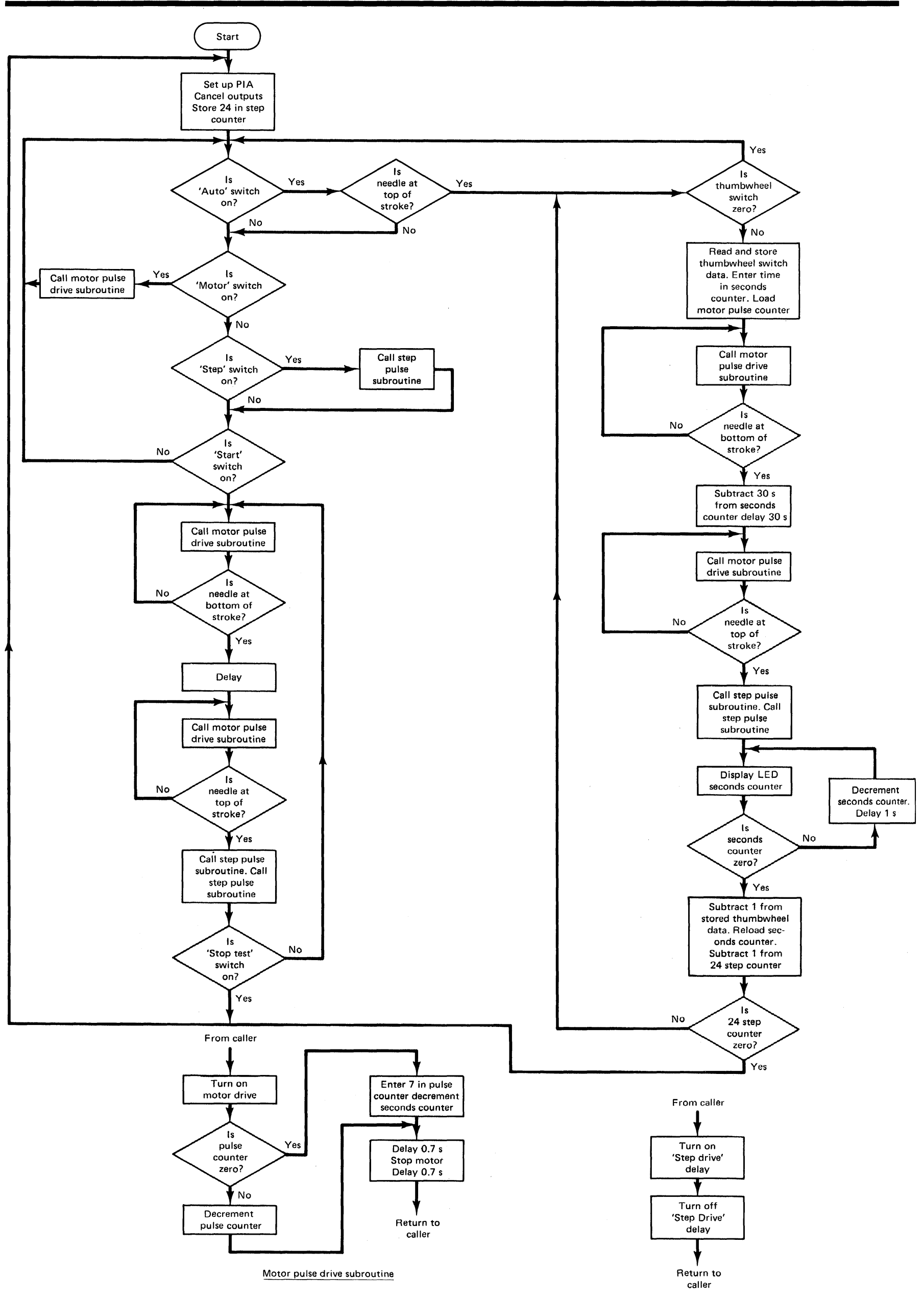

Figure 3. Flow diagram. 
6802 MICRO ASSEMBLER/DISASSEMBLER

1000: \$CO

\begin{tabular}{|c|c|c|c|c|c|}
\hline $1000-$ & $8 \mathrm{E}$ & LDS & & $\$ 007 \mathrm{~F}$ & SET UP P.I.A.s \\
\hline $1003-$ & $\mathrm{CE}$ & LDX & & $\$ 8000$ & CLEAR OUTPUTS \\
\hline 1006 & DF & STX & & 10 & \\
\hline 1008 & 86 & LDA & A & \$FF & \\
\hline $100 \mathrm{~A}-$ & A7 & STA & $\mathbf{A}$ & $00, \mathrm{X}$ & \\
\hline $100 \mathrm{C}-$ & A7 & STA & A & $04, \mathrm{X}$ & \\
\hline $100 \mathrm{E}-$ & 86 & LDA & A & $\$ 00$ & \\
\hline $1010-$ & A7 & STA & A & $02, \mathrm{X}$ & \\
\hline $1012-$ & A7 & STA & A & $06, \mathrm{X}$ & \\
\hline 1014 & C6 & LDA & B & $\$ 04$ & \\
\hline $1016-$ & E7 & STA & B & $01, \mathrm{X}$ & \\
\hline 1018 & E7 & STA & B & $03, \mathrm{X}$ & \\
\hline $101 \mathrm{~A}-$ & E7 & STA & B & $05, X$ & \\
\hline $101 \mathrm{C}$ & E7 & STA & B & $07, \mathrm{X}$ & \\
\hline $101 \mathrm{E}-$ & $6 \mathrm{~F}$ & CLR & & $00, X$ & \\
\hline 1020 & 86 & LDA & A & $\$ 18$ & LOAD 24 SAMPLE COUNTER \\
\hline $1022-$ & 97 & STA & A & 20 & \\
\hline 1024 & A6 & LDA & $\mathbf{A}$ & $02, \mathrm{X}$ & TEST AUTO PUSH BUTTON \\
\hline 1026 & 84 & AND & A & $\$ 01$ & \\
\hline $1028-$ & 26 & BNE & & 1048 & \\
\hline $102 \mathrm{~A}-$ & A6 & LDA & A & $02, \mathrm{X}$ & TEST MOTOR PUSH BUTTON \\
\hline $102 \mathrm{C}-$ & 84 & AND & $\mathbf{A}$ & $\$ 08$ & \\
\hline $102 \mathrm{E}-$ & 27 & BEQ & & 1035 & \\
\hline $1030-$ & BD & JSR & & F120 & \\
\hline $1033-$ & 20 & BRA & & 1024 & \\
\hline 1035 & A6 & LDA & A & $02, \mathrm{X}$ & TEST STEP PUSH BUTTON \\
\hline $1037-$ & 84 & AND & $\mathbf{A}$ & $\$ 10$ & \\
\hline $1039-$ & 27 & BEQ & & 1040 & \\
\hline $103 \mathrm{~B}-$ & BD & JSR & & F0F0 & \\
\hline $103 \mathrm{E}-$ & 20 & BRA & & 1035 & \\
\hline $1040-$ & A6 & LDA & A & $02, \mathrm{X}$ & TEST START TEST PUSH BUTTON \\
\hline $1042-$ & 84 & AND & $\mathbf{A}$ & $\$ 40$ & \\
\hline $1044-$ & 26 & BNE & & $10 \mathrm{C} 2$ & \\
\hline $1046-$ & 20 & BRA & & 1024 & \\
\hline $1048-$ & A6 & LDA & A & $02, \mathrm{X}$ & (START OF AUTOMATIC CYCLE) \\
\hline $104 \mathrm{~A}-$ & 84 & AND & A & $\$ 02$ & TEST NEEDLE UP \\
\hline $104 \mathrm{C}-$ & 27 & BEQ & & $102 \mathrm{~A}$ & \\
\hline 104E- & A6 & LDA & A & $06, \mathrm{X}$ & READ THUMBWHEEL SWITCH \\
\hline $1050-$ & 84 & AND & $\mathbf{A}$ & $\$ 0 F$ & STORE 10 MINUTE INTERVAL COUNTER \\
\hline $1052-$ & 27 & BEQ & & 1024 & \\
\hline 1054 & 97 & STA & $\mathbf{A}$ & 17 & \\
\hline $1056-$ & 86 & LDA & $\mathbf{A}$ & $\$ 07$ & LOAD MOTOR PULSE COUNTER \\
\hline $1058-$ & 97 & STA & $\mathbf{A}$ & 16 & \\
\hline $105 \mathrm{~A}-$ & $\mathrm{CE}$ & LDX & & $\$ 025 \mathrm{C}$ & \\
\hline 105D- & DF & STX & & 18 & \\
\hline $105 \mathrm{~F}-$ & BD & JSR & & F120 & CALL MOTOR PULSE DRIVE SUBROUTINE \\
\hline $1062-$ & A6 & LDA & A & $02, \mathrm{X}$ & TEST NEEDLE DOWN \\
\hline 1064 & 84 & AND & $\mathbf{A}$ & $\$ 04$ & \\
\hline $1066-$ & 27 & BEQ & & $105 \mathrm{~F}$ & SUBTRACT 30 SECONDS FROM SECONDS COUNTER \\
\hline $1068-$ & OC & CLC & & & \\
\hline $1069-$ & 96 & LDA & A & 19 & \\
\hline 106B- & 80 & SUB & A & \$1E & \\
\hline 106D- & 97 & STA & A & 19 & \\
\hline 106F & 96 & LDA & A & 18 & \\
\hline 1071- & 82 & SBC & A & $\$ 00$ & \\
\hline $1073-$ & 97 & STA & A & 18 & \\
\hline $1075-$ & 86 & LDA & A & $\$ 38$ & \\
\hline 1077- & $\mathrm{CE}$ & LDX & & \$FFFE & DELAY 30 SECONDS \\
\hline $107 \mathrm{~A}-$ & 09 & DEX & & & \\
\hline $107 \mathrm{~B}-$ & 26 & BNE & & $107 \mathrm{~A}$ & \\
\hline 107D & $4 \mathrm{~A}$ & $\mathrm{DEC}$ & A & & \\
\hline $107 \mathrm{E}-$ & 26 & BNE & & 1077 & \\
\hline $1080-$ & BD & JSR & & F120 & CALL MOTOR PULSE DRIVE SUBROUTINE \\
\hline $1083-$ & A6 & LDA & A & $02, \mathrm{X}$ & TEST NEEDLE UP \\
\hline $1085-$ & 84 & AND & A & $\$ 02$ & \\
\hline $1087-$ & 27 & BEQ & & 1080 & \\
\hline $1089-$ & BD & JSR & & F0F0 & CALL STEP PULSE ROUTINE \\
\hline $108 \mathrm{C}-$ & BD & JSR & & F0F0 & CALL STEP PULSE SUBROUTINE \\
\hline $108 \mathrm{~F}-$ & $\mathrm{DE}$ & LDX & & 10 & PULSE AUTO LED \\
\hline $1091-$ & 96 & LDA & $\mathbf{A}$ & 19 & \\
\hline $1093-$ & A7 & STA & A & $04, X$ & \\
\hline $1095-$ & DE & LDX & & 18 & TEST SECONDS COUNTER ZERO \\
\hline $1097-$ & 26 & BNE & & 10B1 & \\
\hline 1099 & D6 & LDA & B & 17 & COUNT DOWN 10 MINUTE INTERVAL COUNTER \\
\hline 109B- & $5 A$ & DEC & B & & \\
\hline $109 \mathrm{C}-$ & D7 & STA & B & 17 & \\
\hline $109 \mathrm{E}-$ & 27 & BEQ & & $10 \mathrm{~A} 7$ & \\
\hline 10A0- & $\mathrm{CE}$ & LDX & & $\$ 025 \mathrm{C}$ & RELOAD SECONDS (10 MINUTE) COUNTER \\
\hline 10A3- & DF & STX & & 18 & \\
\hline 10A5- & 20 & BRA & & $108 \mathrm{~F}$ & \\
\hline $10 \mathrm{~A} 7-$ & $\mathrm{DE}$ & LDX & 10 & & \\
\hline 10A9- & $7 \mathrm{~A}$ & DEC & & 0020 & COUNT DOWN 24 SAMPLE COUNTER \\
\hline
\end{tabular}

Figure 4 (continued over). 
H. L. Reed et al. A versatile automatic gas-sampling system

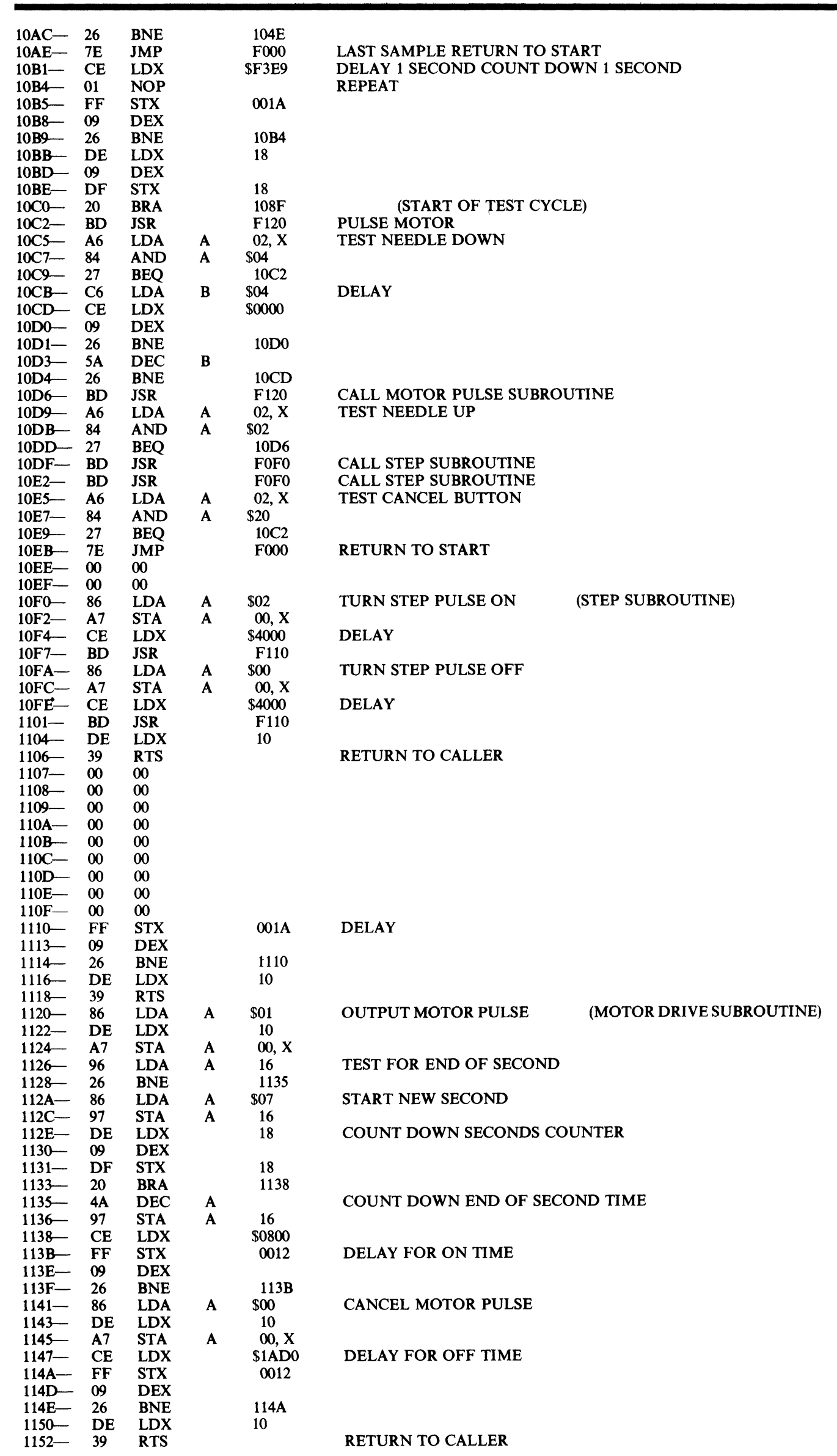

Figure 4. Assembly listing. 


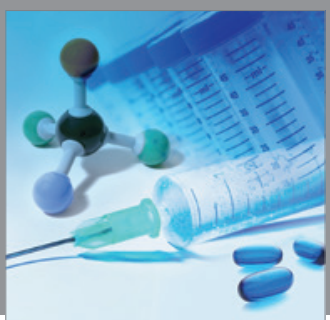

International Journal of

Medicinal Chemistry

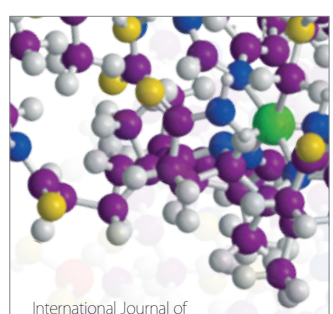

Carbohydrate Chemistry

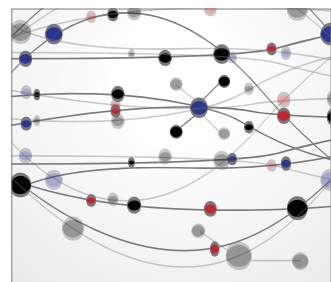

The Scientific World Journal
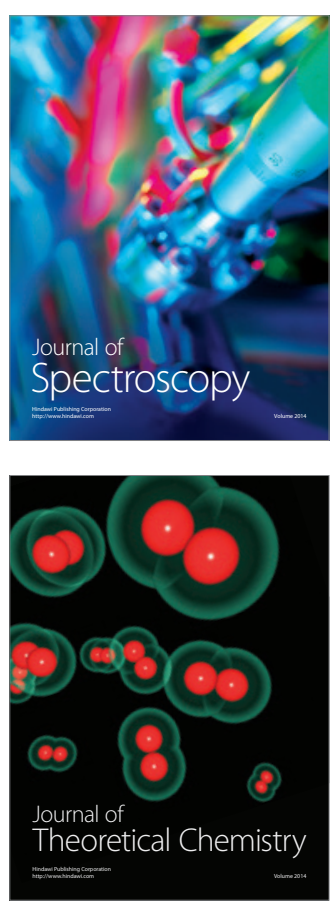
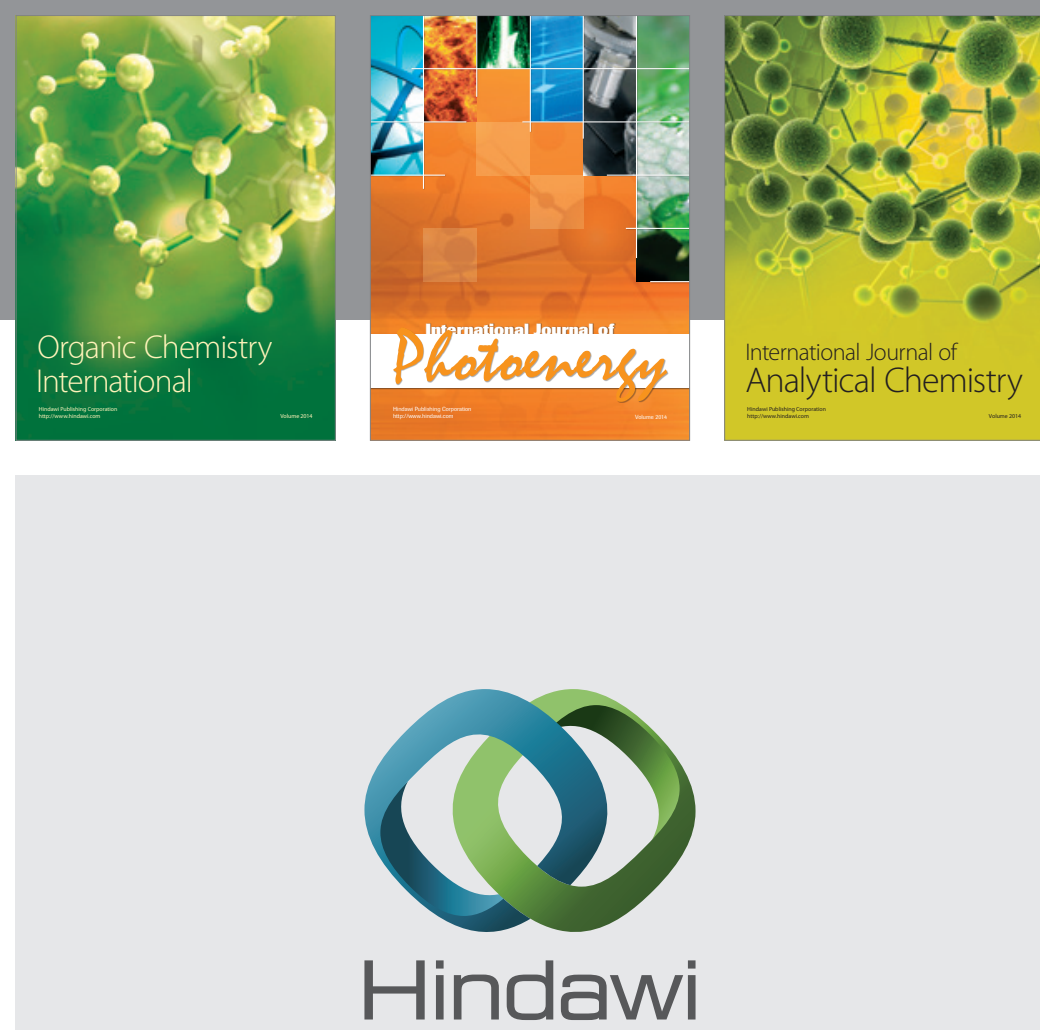

Submit your manuscripts at

http://www.hindawi.com
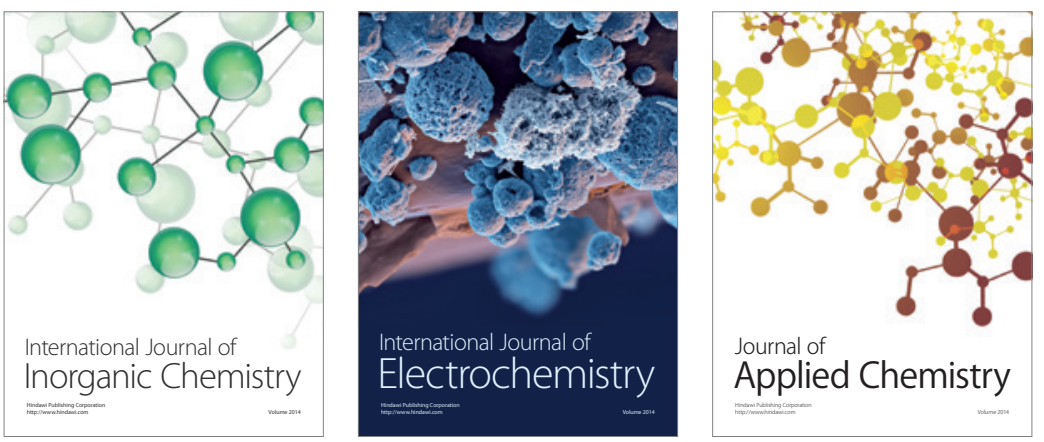

Journal of

Applied Chemistry
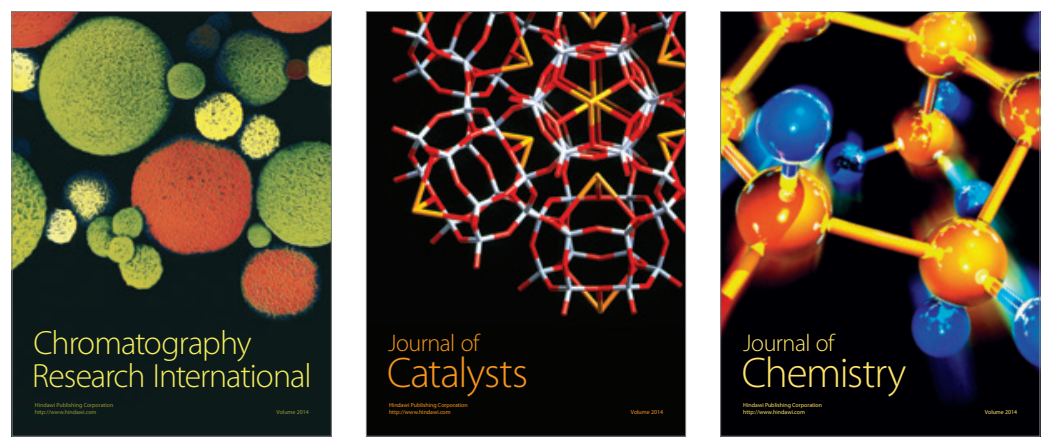
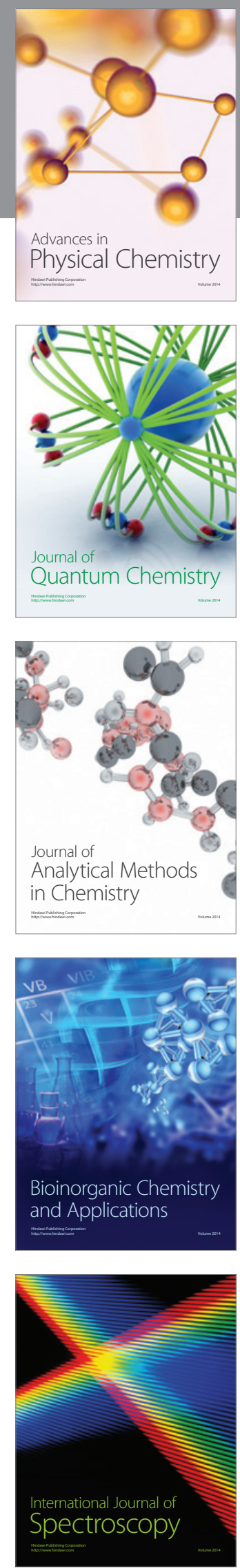